\title{
Les cartes des Cassini. La science au service de l'État et des provinces
}

\section{Gérard Aubin}

\section{(2) OpenEdition}

\section{Journals}

Édition électronique

URL : http://journals.openedition.org/rao/6411

DOI : 10.4000/rao.6411

ISSN : 1775-3732

\section{Éditeur}

Presses universitaires de Rennes

\section{Édition imprimée}

Date de publication : 18 décembre 2020

Pagination : 255

ISBN : 978-2-7535-8232-3

ISSN : 0767-709X

\section{Référence électronique}

Gérard Aubin, "Les cartes des Cassini. La science au service de l'État et des provinces », Revue archéologique de l'Ouest [En ligne], 36 | 2020, mis en ligne le 18 décembre 2020, consulté le 04 avril 2021. URL : http://journals.openedition.org/rao/6411 ; DOI : https://doi.org/10.4000/rao.6411 
rapidement, la multiplication des plans et des tableaux, le soin particulier apporté aux renvois vers les figures, la belle qualité de l'illustration.

Ce compte rendu ne donne qu'un aperçu de l'ampleur du travail accompli et de la richesse de l'ouvrage. Bel exemple d'intégrité scientifique, par la mise à disposition de données détaillées et vérifiables, il pourra être source de nouvelles investigations. À l'heure des bases de données en ligne, on pourrait s'étonner que cette documentation soit livrée sous forme papier, un peu encombrante; mais à l'usage, le feuilletage permet peut-être davantage de croisements et d'interrogations, voire de regards critiques que le défilement de feuilles de calcul; au demeurant, la liste des US du sanctuaire est disponible et téléchargeable (http://www.chauvigny-patrimoine. fr/Editions/memoires.php). Je souscris pleinement à l'appréciation liminaire de William Van Andringa selon laquelle ce livre " achève de consacrer le site comme un jalon incontournable de l'étude des lieux de culte de Gaule romaine ». J'y ajoute le souhait qu'il serve de stimulant aux dix dossiers de sanctuaires dont la publication est souhaitée dans le ressort de la Revue archéologique de l'Ouest: un en Bretagne, quatre en Pays de la Loire, cinq en Normandie.

Gérard AuBIN

Pelletier M., 2019 - Les cartes des Cassini. La science au service de l'État et des provinces, nouvelle édition, Paris, éditions du CTHS, 383 p., 54 fig.

Le Comité des travaux historiques et scientifiques a eu l'heureuse idée de réimprimer, dans un format poche, l'étude de Monique Pelletier, parue initialement en grand format aux Presses de l'École nationale des ponts et chaussées en 1990, puis rééditée et mise à jour successivement en 2002 et 2013. Monique Pelletier, récemment décédée, archiviste paléographe, conservatrice générale des bibliothèques en charge du Département des cartes et plans à la Bibliothèque nationale de 1976 à 1999, était particulièrement désignée pour raconter en détail l'histoire de cette aventure cartographique qui occupe la seconde moitié du $\mathrm{XVIII}^{\mathrm{e}} \mathrm{s}$. : l'état des lieux au XVI ${ }^{\mathrm{e}}$, les antécédents du XVII ${ }^{\mathrm{e}}$, par exemple les cartes des Sanson, le projet de Colbert - fondateur en 1666 de l'Académie royale des Sciences qu'il charge d'étudier les méthodes de la cartographie -, la dynastie des Cassini (ils furent quatre à se succéder), la décision de Louis XV en 1747 de faire lever une carte détaillée du royaume, la réalisation de cette carte en 181 feuilles avec ses contraintes et ses difficultés notamment financières, puis après l'arrêt dû à la Révolution, le lent passage à la carte de l'État-Major du XIX ${ }^{e}$.

Pour qui s'intéresse à la construction du paysage, la connaissance des méthodes de terrain, des contraintes et des limites de cette cartographie est un préalable à son utilisation comme document historique. On notera par exemple le soin apporté aux relevés, aux enquêtes dans les paroisses et aux vérifications confiées à un corps spécialisé, non seulement des levés mais aussi de l'orthographe des toponymes suivant "l'usage ordinaire" (voir par exemple fig. 31. Feuille de vérifications de la planche de Saint-Malo). Les principales critiques concernèrent la médiocre représentation du relief (pas de nivellement systématique), ou l'insuffisante figuration du réseau routier secondaire, ce que Cassini III justifiait car un grand nombre de chemins de terre, souvent impraticables, variaient selon les saisons (p. 148).

Tout au long de l'ouvrage, on glanera des informations sur nos régions de l'Ouest : la plus ancienne carte de diocèse connue est celle du diocèse du Mans (1539), parvenue à nous par l'Atlas de Bouguereau (1594); l'aménagement de la Vilaine entre Rennes et Redon (atlas de 1543); le projet d'équipement de la Vie, rivière vendéenne, dessiné par JeanBaptiste Florentin (1542) (p. 37 et fig. 5); une superbe carte restée manuscrite du pays de Normandie par Jean Jolivet en 1545 (p. 21); les aléas de la réalisation du canevas géométrique en Normandie (p. 93), etc. Un développement particulier (p. 213-216) est réservé aux cartes de Bretagne : un projet inabouti de 1721, la carte géométrique d'Ogée en 1771, et enfin la carte de Cassini. Les feuilles de Bretagne sont les dernières levées dans les années 1780, en dépit des relations difficiles avec les États de Bretagne dont Cassini IV se plaint amèrement : "Rien de pis que de traiter d'affaire avec des gens qui n'y entendent rien. "

Plus généralement, cet ouvrage permet de réfléchir aux enjeux de la représentation des territoires, aux apports et limites des cartes en rappelant qu'elles sont dressées en fonction de visées spécifiques (administratives, militaires, religieuses) et soumises aux exigences des commanditaires.

Des annexes (I - liste des feuilles de la carte; II - liste chronologique des travaux et des ingénieurs; III - table alphabétique des abréviations de la carte), une copieuse bibliographie (p. 336-358), deux index contribuent à faire de cet ouvrage, sobrement illustré, un indispensable compagnon pour l'utilisateur des cartes de Cassini.

Gérard Aubin 